\title{
Antismoking drug still recommended to Canadians despite side effects and US advisory
}

A spate of complaints about the smoking-cessation drug varenicline (Champix) prompted bans on its use by pilots and commercial drivers in the United States last year, but reports of adverse reactions have not resulted in such dramatic consequences for Canadian users.

"At this time, Health Canada considers that, when used as directed, the benefits associated with Champix as a smoking cessation therapy continue to outweigh the overall risks," stated Health Canada spokesperson Paul Duchesne via email.

Pfizer introduced the drug in the United States, where it's marketed under the brand name Chantix, in September 2006. It is now marketed in 73 countries and, according to Pfizer, has been taken by some 10 million people worldwide.

Side effects of the drug include nausea and abnormal dreams. Because of growing evidence of a link to aggression, depression and suicidal tendencies, on Feb. 1, 2008, the US Food and Drug Administration issued a public health advisory that warned users and doctors about the neuropsychiatric symptoms. When the drug went on sale in Australia, in January 2008, the Therapeutic Goods Administration ordered Pfizer to issue "Dear Doctor" letters. The United Kingdom's Medicines and Healthcare Products Regulatory Agency received 3541 adverse effects reports, including 10 suicides, within a year of varenicline hitting the market in September 2006.

"It is not known whether these events are occurring at a rate and severity which is different from the background rate for smoking cessation in the general population, or in the psychiatric population (treated or untreated), or different from the rates for other drugs in the class of smoking cessation," stated Pfizer Canada Inc. spokesperson Christian Marcoux via email.

Last October, the US Institute for Safe Medication Practices linked varenicline to cardiac rhythm disturbances and cases of acute myocardial infarction. It reported that US users were involved in 1001 serious incidents in the first quarter of 2008, including many traffic accidents.

The US Federal Aviation Administration promptly banned pilots and air traffic controllers from using varenicline. Transport Canada, which has doctors who assess aviation professionals individually, has not followed suit. "We will not intervene if the pilot is deemed fit to fly," says spokesperson Maryse Durette.

The US Federal Motor Carrier Safety Administration banned varenicline for all drivers of commercial motor vehicles. But the Canadian Council of Motor Transport Administrators has not banned the drug, choosing instead to evaluate drivers on a case-by-case basis. "It's not the medication. It's the medical condition you have that doesn't make you fit," says Ian Tomlinson, the council's program manager.

Health Canada approved varenicline for sale in Canada on Jan. 24, 2007. According to Pfizer, Canadian doctors have to date issued more than 1.1 million prescriptions for the drug. Health Canada received 818 reports of adverse effects from varenicline users as of Oct. 31, 2008, and has issued 2 warnings about the drug, the most recent (Jan. 6) stating that it was "in the process of further strengthening the labelling for the drug with respect to the risk of serious psychiatric adverse effects."

The effect of adverse event reports on sales has yet to be felt in Canada, but sales of varenicline are down sharply in the US. In the third-quarter of 2008, sales totalled US\$96 million, a drop of nearly half from the same quarter in 2007.

In spite of the warnings, some Canadian health organizations still recommend varenicline to people attempting to quit smoking. The Canadian Lung Association endorses the drug under its generic name on its website. The Canadian Cancer Society recommends smoking-cessation products in general but does not endorse specific products, according to spokesperson Alexa
Giorgi. Dr. Peter Selby, who heads the Nicotine Dependence Clinic at the Centre for Addiction and Mental Health, says varenicline is appropriate for some people. "We are not comparing the risks to a placebo," he says. "We are comparing it to not quitting smoking. We have to intervene appropriately."

Selby, who has received fees for research, consultation and training from Pfizer, says that people who opt for pharmaceutical help to quit smoking must be vigilant in monitoring side effects and reporting them to their doctors. "The take-home message is that you have to weigh the risks and benefits with the patient."

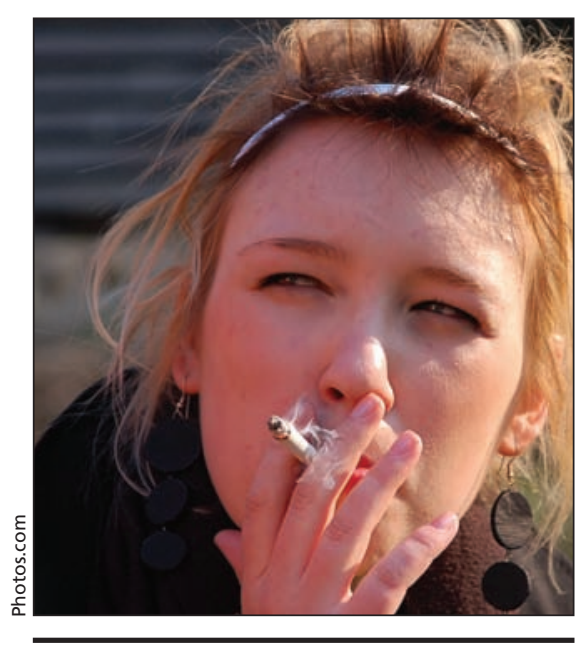

The benefits of the smoking-cessation drug varenicline outweigh the risks, according to Health Canada.

Health Canada continues to monitor the safety of varenicline and is updating prescribing information. When this is completed, new advice will be sent to health professionals and released to the public. Duschesne says Health Canada does not automatically compile information comparing the number of adverse effects reported for different drugs, but writes: "It is however fair to say that adverse events reported by Champix users have been increasing significantly in the last few months." - Roger Collier, CMAJ

DOI:10.1503/cmaj.090114 